\title{
A superior preparation method for daidzein-hydroxypropyl- $\beta$ - -cyclodextrin complexes with improved solubility and dissolution: Supercritical fluid process
}

\author{
HAO PAN ${ }^{1,2, *}$ \\ HAN-BING WANG ${ }^{3, \#}$ \\ YI-BIN YU $\mathrm{U}^{3}$ \\ BING-CHAO CHENG ${ }^{3}$ \\ XIAO-YU WANG ${ }^{3}$ \\ YING LI ${ }^{1,4, *}$ \\ ${ }^{1}$ Department of Pharmacy \\ School of Medicine, Shenzhen University \\ Shenzhen, China \\ ${ }^{2}$ College of Pharmacy \\ Liaoning University, Shenyang, China \\ ${ }^{3}$ School of Pharmacy, Shenyang \\ Pharmaceutical University, Shenyang \\ China \\ ${ }^{4}$ Division of Life Science $\mathcal{E}$ Health \\ Graduate School at Shenzhen \\ Tsinghua University, Shenzhen, China
}

Accepted September 10, 2016

Published online October 31, 2016

\begin{abstract}
Advantages of the supercritical fluid (SCF) process compared to the conventional solution stirring method (CSSM) in the preparation of daidzein-hydroxypropyl- $\beta$-cyclodextrin $(\mathrm{HP} \beta \mathrm{CD})$ complexes were investigated. Formation of daidzein/HP $\beta C D$ inclusion complexes was confirmed by Fourier transformed-infrared spectroscopy (FTIR), differential scanning calorimetry (DSC), X-ray diffraction (XRD) and scanning electron microscopy (SEM). Particle size, inclusion yield, drug solubility and dissolution of daidzein/HP $\beta C D$ complexes were evaluated. Compared to CSSM, the SCF process resulted in higher inclusion yield and higher solubility. Also, extended dissolution of daidzein from the SCF processed HP $\beta C D$ inclusion complexes was observed, with only $22.94 \%$ released in $45 \mathrm{~min}$, compared to its rapid release from those prepared by CSSM, with $98.25 \%$ drug release in $15 \mathrm{~min}$. This extended release of daidzein from SCF prepared inclusion complexes was necessary to avoid drug precipitation and improve drug solubilisation in the gastrointestinal tract. The results showed that the SCF process is a superior preparation method for daidzein-hydroxypropyl$\beta$-cyclodextrin complexes.
\end{abstract}

Keywords: daidzein, hydroxypropyl- $\beta$-cyclodextrin, supercritical fluid, inclusion complex

Daidzein (4',7-dihydroxylisoflavone), isolated mainly from leguminous plants, is a natural plant estrogen. It has a wide spectrum of physiological and pharmacological functions, including antifibrotic (1), antiestrogenic (2), anticancer $(3,4)$, anti-inflammatory (5), cardioprotective and enzyme-inhibitory $(6,7)$ effects. However, the poor aqueous solubility in the gastrointestinal (GI) tract severely restricts the absorption of daidzein, and thereby its curative effects (8). Therefore, it is urgent to develop an appropriate method for enhancing drug solubility and overcoming the daidzein gastrointestinal absorption barrier.

\footnotetext{
* Correspondence; e-mail: li.ying@szu.edu.cn

* Authors that contributed equally to this work.
} 
One of the most important approaches to improving solubility and oral absorption of drugs is the use of cyclodextrins (CDs) (9). CDs are cyclic oligomers of glucose that can form water-soluble inclusion complexes with small molecules and portions of large compounds (10). Owing to their good biocompatibility, low toxicity and non-immune responses to animals and humans (11), CDs have been widely used in pharmaceutical applications for oral drug solubilisation in the last half century (12). Several techniques, including kneading, grinding, freeze drying and crystallization have been used to prepare drug/CD inclusion complexes. However, most of these methods require multistage processes, which are time- and energy-consuming, resulting in residual solvents in products. Besides, solubility improvement for poorly water soluble drugs has been limited and severely influenced by preparation methods.

Supercritical fluid (SCF) process is proposed as a novel alternative method for the preparation of drug-cyclodextrin complexes. Supercritical carbon dioxide $\left(\mathrm{SC}-\mathrm{CO}_{2}\right)$ is suggested as a new complexation medium instead of other conventional liquid solvents (13). In this study, the SCF process was used to prepare daidzein-HP $\beta C D$ complexes for improving drug solubility. In addition, differences between daidzein-HP $\beta C D$ complexes in improving drug solubilisation and dissolution behaviour by the SCF process and the conventional solution stirring method (CSSM) were compared.

\section{EXPERIMENTAL}

\section{Materials}

Daidzein (purity $98 \%$, batch number: Dd20090823) was obtained from Shanxi Zelang Phytoextraction Co., Ltd. HP $\beta C D$ (purity $98 \%$, batch number: H5F178P) was purchased from Wacker Chemical Co., Ltd. Carbon dioxide (Instrument grade, purity $99.5 \%$ ) was purchased from Zhonghong Industrial Gas Shenzhen Co., Ltd. Ethanol (analytical grade, purity $99.7 \%$ ) was purchased from the Guangzhou Chemical Reagent 2 Factory. Methanol (HPLC grade) was purchased from Merck Co., Ltd.

\section{Preparation by the conventional co-grinding method (CG)}

Daidzein and CDs of 1:1 molar ratio were accurately weighed. CD solution was prepared by mixing $584.0 \mathrm{mg} \mathrm{CD}$ and $2.4 \mathrm{~mL}$ water in a mortar. Then, $101.0 \mathrm{mg}$ of daidzein was added. A homogenous paste was prepared and further ground for $30 \mathrm{~min}$. The obtained mass was oven dried at $40^{\circ} \mathrm{C}$ for $24 \mathrm{~h}$. It was then washed 3 times with $10 \mathrm{~mL}$ anhydrous ether, and dried at $40^{\circ} \mathrm{C}$.

\section{Preparation by the conventional co-precipitation method (CP)}

Daidzein and CDs of 1:1 molar ratio were accurately weighed. $15 \mathrm{~mL}$ of CD solution was prepared with $584.0 \mathrm{mg} \mathrm{HP} \beta C D$ and water. Then, $101.0 \mathrm{mg}$ daidzein dissolved in 60 $\mathrm{ml}$ anhydrous ethanol was added slowly and a suspension was formed. The suspension was stirred at $40{ }^{\circ} \mathrm{C}$ for $30 \mathrm{~min}$ and kept under stirring at room temperature for $24 \mathrm{~h}$. The obtained mass was filtered through a $0.45 \mu \mathrm{m}$ membrane filter and oven dried at $40^{\circ} \mathrm{C}$. It was then washed 3 times with $10 \mathrm{~mL}$ anhydrous ether and dried at $40{ }^{\circ} \mathrm{C}$. 


\section{Preparation by the conventional ultrasonic method}

Daidzein and CDs of 1:1 molar ratio were accurately weighed. $10 \mathrm{~mL}$ of CD solution was prepared with $292.0 \mathrm{mg} \mathrm{HP} \beta C D$ and water. After addition of $50.0 \mathrm{mg}$ daidzein, a suspension was formed. Then, the suspension was stirred in an ultrasonic machine for $5 \mathrm{~h}$ at $100 \mathrm{w}$. The obtained mass was filtered through a $0.45 \mu \mathrm{m}$ membrane filter and oven dried at $40{ }^{\circ} \mathrm{C}$.

\section{Preparation by CSSM}

A sample of $202.0 \mathrm{mg}$ daidzein was added to $10 \mathrm{~mL} 10 \%(\mathrm{~m} / \mathrm{V}) \mathrm{HP} \beta C \mathrm{C}$ aqueous solution ( $\mathrm{pH} 12.0$ ) with a molar ratio of 1:1. $1168.0 \mathrm{mg} \mathrm{HP} \beta \mathrm{CD}$ was dissolved in $10 \mathrm{~mL}$ water to prepare a $10 \%(\mathrm{~m} / \mathrm{V}) \mathrm{HP} \beta \mathrm{CD}$ aqueous solution. Then, this mixture was stirred continuously at $45^{\circ} \mathrm{C}$ for $4 \mathrm{~h}$ (300 rpm). After cooled to ambient temperature, the suspension was filtered through a $0.45 \mu \mathrm{m}$ membrane filter. After that, the filtrate was lyophilized.

\section{Preparation by the SCF process}

A sample of $178.0 \mathrm{mg}$ daidzein and $1002.0 \mathrm{mg} \mathrm{HP} \beta \mathrm{CD}$ of a molar ratio of 1:1 were ground in a mortar until homogeneous to get physical mixtures. Daidzein/HP $\beta C D$ inclusion complexes were prepared using a supercritical fluid extraction apparatus (Fig. 1). Physical mixtures were placed into an extraction vessel (6). The system was then heated to $200{ }^{\circ} \mathrm{C}$ over an oil bath. Valve 8 and valve 2 were opened and the air inside was drained due to $\mathrm{CO}_{2}$ influx. Five minutes later, valve 8 was closed, and the $\mathrm{CO}_{2}$ was pumped into the vessel. After reaching the desired pressure of $20 \mathrm{MPa}$, valve 2 was closed. After $8 \mathrm{~h}$, valve 8 was opened to depressurize the system. The depressurization process was controlled for $30 \mathrm{~s}$. The whole process was repeated three times. Solubility and yield of the SCF processed product were determined.

\section{Characterization of daidzein/HP $\beta C D$ inclusion complexes} Solubility determination of inclusion complexes

Solubility and product yield of all the above prepared CD inclusion complexes were determined. One gram of inclusion complex product prepared by the above preparation methods was first dispersed into $1 \mathrm{~mL}$ distilled water. After $24 \mathrm{~h}$, this mixture was filtered through a $0.45 \mu \mathrm{m}$ Millipore filter. The filtrate was then diluted properly and its concentra-

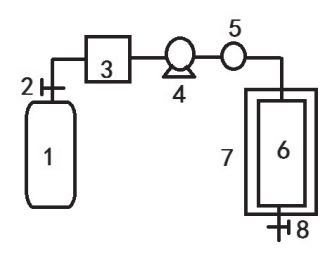

Fig. 1. Schematic drawing of the supercritical fluid extraction apparatus: $1-\mathrm{CO}_{2}$ source, 2 and 8 - valves, 3 - cooler, 4 - pump, 5 - pressure gauge, 6 - extraction vessel and 7 - oil bath. 
tion was measured with Agilent $1200 \mathrm{HPLC}$. The detective wavelength was $250 \mathrm{~nm}$. The mobile phase consisted of methanol and water (55:45). Inclusion yield was then calculated. Every measurement was done in triplicate and 3 batches of products were investigated.

\section{Characterization by scanning electron microscopy}

The morphology of daidzein, HP $\beta C D$, physical mixtures, SCF processed daidzein and the complexes prepared by CSSM and SCF process were visualized using a scanning electron microscope (JSM-6460LV, JEOL, Japan). Samples were coated with gold-palladium using a sputter module prior to analysis.

\section{Characterization by differential scanning calorimetry}

In order to conduct DSC properly, the decomposition temperatures of daidzein and $\mathrm{HP} \beta \mathrm{CD}$ were determined using thermogravimetric analysis. Daidzein and the SCF processed daidzein were investigated with DSC 204F1 (NETZSCH, Germany). Samples were accurately weighed in a DSC aluminium pan and were crimped and then heated under an inert nitrogen atmosphere $\left(20 \mathrm{~mL} \mathrm{~min}^{-1}\right)$ at a scanning rate of $10^{\circ} \mathrm{C} / \mathrm{min}$ from room temperature to $350{ }^{\circ} \mathrm{C}$. An aluminium pan containing the same amount of aluminium oxide was used as reference.

\section{Characterization by powder X-ray diffractometry}

X-ray diffraction patterns of daidzein, HP $\beta C D$, physical mixtures, SCF processed daidzein and inclusion complex products of CSSM and the SCF process were obtained using a D/MAX-1200X diffractometer (Science Co., Ltd, Japan). The measuring conditions were as follows: $\mathrm{Cu}-\mathrm{K} \alpha 1$ radiation source; divergence slit $0.50 \mathrm{~mm}$; receive slit $0.3 \mathrm{~mm}$; voltage $35 \mathrm{kV}$; current $25 \mathrm{~mA}$; $2 \theta$ angle from 30 to 600 .

\section{Characterization by Fourier-transform infrared spectroscopy}

FTIR spectra for daidzein, HPßCD, physical mixtures, SCF processed daidzein and inclusion complex products of CSSM and the SCF process were obtained using a FTIR 8400 spectrometer (Shimadzu, Japan). The samples for analysis were mixed with dry $\mathrm{KBr}$ at about a 1:100 (sample: $\mathrm{KBr}$ ) ratio and pressed to form KBr pellets. For each sample, 64 scans were collected at a resolution of $2 \mathrm{~cm}^{-1}$ over the wavenumber region of $2500-400 \mathrm{~cm}^{-1}$.

\section{Particle size analysis}

Particle sizes of daidzein, HP $\beta C D$, physical mixtures, SCF processed daidzein and inclusion complex products of CSSM and the SCF process were measured using a laser particle size analyser (Mastersizer 2000, Malvern, UK) equipped with Sirocco 2000.

\section{Dissolution rate study}

Dissolution rate studies of daidzein alone and from various daidzein-cyclodextrins systems were conducted in a dissolution apparatus (RCZ-8A, China) using the paddle method, according to USP XXVI at $37 \pm 0.5^{\circ} \mathrm{C}$, with stirring at $100 \mathrm{r} / \mathrm{min} .3 .22 \mathrm{mg}$ of 
daidzein or an equivalent amount of daidzein-cyclodextrin was added to $500 \mathrm{~mL}$ of water. $5 \mathrm{~mL}$ of the solution was taken out and replaced with the same volume of fresh medium at 5, 10, 15, 20, 30, $45 \mathrm{~min}$. The withdrawn solution was immediately filtered through a $0.45 \mu \mathrm{m}$ membrane filter and suitably diluted. Daidzein concentration in samples was determined by HPLC.

\section{RESULTS AND DISCUSSION}

\section{Solubility and product yield of inclusion complexes}

As shown in Table I, the solubility of CSSM was significantly higher than those of other conventional preparation methods. Thus, the CSSM method was deemed to be the optimized conventional preparation method. In further studies, a comparison of CSSMprepared daidzein/HP $\beta C D$ inclusion complexes and SCF processed daidzein/HP $\beta C D$ inclusion complexes was conducted. The solubility of SCF processed inclusion complexes was $44.81 \mathrm{mg} / \mathrm{mL}$, which was nearly double that of CSSM.

Table I. Solubility and product yield in different conventional preparation methods

\begin{tabular}{lcccc}
\hline & $\begin{array}{c}\text { Co-grinding } \\
\text { method }\end{array}$ & $\begin{array}{c}\text { Ultrasonic } \\
\text { method }\end{array}$ & $\begin{array}{c}\text { Co-precipitation } \\
\text { method }\end{array}$ & $\begin{array}{c}\text { Solution stirring } \\
\text { method (CSSM) }\end{array}$ \\
\hline Solubility $\left(\mathrm{mg} \mathrm{mL}^{-1}\right)$ & $19.93 \pm 2.23$ & $4.54 \pm 0.68$ & $0.16 \pm 0.08$ & $23.65 \pm 3.37$ \\
Yield (\%) & $56.30 \pm 8.89$ & $52.86 \pm 7.45$ & $85.20 \pm 9.63$ & $70.91 \pm 8.12$ \\
\hline
\end{tabular}

\section{Scanning electron microscopy}

The morphology by SEM for daidzein, HP $\beta C D$, physical mixtures, SCF processed daidzein and inclusion complexes prepared by CSSM and the SCF process is given in Fig. 2. From SEM analysis, pure daidzein and daidzein processed with $\mathrm{SC}-\mathrm{CO}_{2}$ appeared as long and thin prismoid crystals, indicating that the daidzein morphology was hardly altered by the SCF process. Pure HP $\beta C D$ (Fig. $2 b$ ) was an irregular spherical particle, while physical mixtures (Fig. 2c) showed a blend of spheres of HP $\beta C D$ and prismoid daidzein crystals. Inclusion complex products prepared by both CSSM (Fig. 2e) and the SCF process (Fig. 2f) were plate-like and, apparently, the latter was more homogeneous and finer.

\section{Thermal analysis}

The thermogravimetric analyser (TGA) graphs for daidzein and HP $\beta C D$ are represented in Fig. 3. Daidzein began to decompose at $340^{\circ} \mathrm{C}$, and $\mathrm{HP} \beta \mathrm{CD}$ began to decompose at $300{ }^{\circ} \mathrm{C}$. Thus, we only presented the DSC measurement of pure and SCF processed daidzein. The DSC curves for daidzein (Fig. 4a) and SCF processed daidzein (Fig. 4b) showed a characteristic melting endothermic peak when above $337.4{ }^{\circ} \mathrm{C}$. This indicated that the SCF process did not change daidzein crystallinity. 
H. Pan et al:: A superior preparation method for daidzein-hydroxypropyl- $\beta$-cyclodextrin complexes with improved solubility and dissolution: Supercritical fluid process, Acta Pharm. 67 (2017) 85-97.
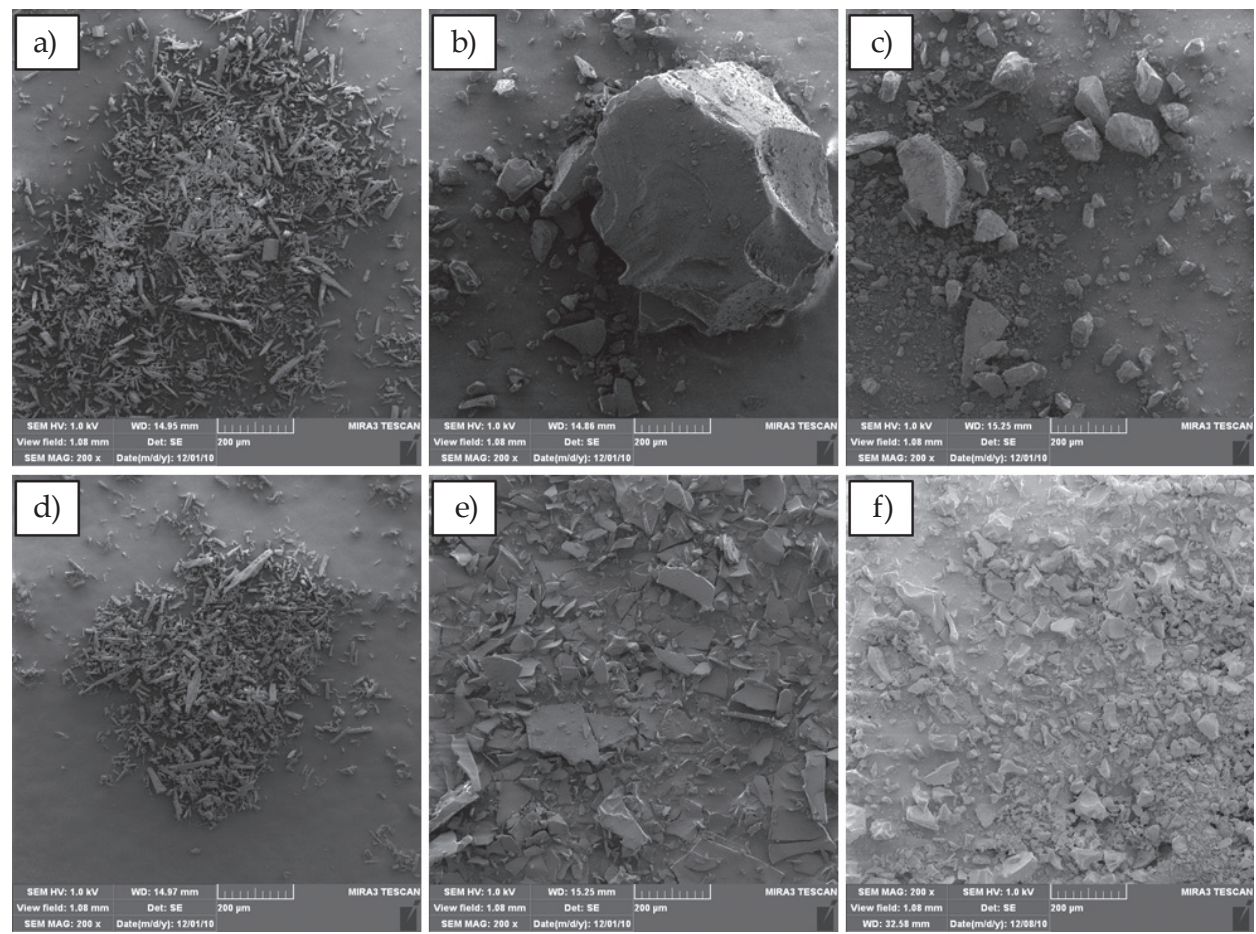

Fig. 2. SEM pictures of different samples: a) daidzein, b) HP $\beta C D$, c) physical mixtures, d) SCF processed daidzein, e) product prepared by the conventional solution stirring method, and f) product prepared by the SCF process.

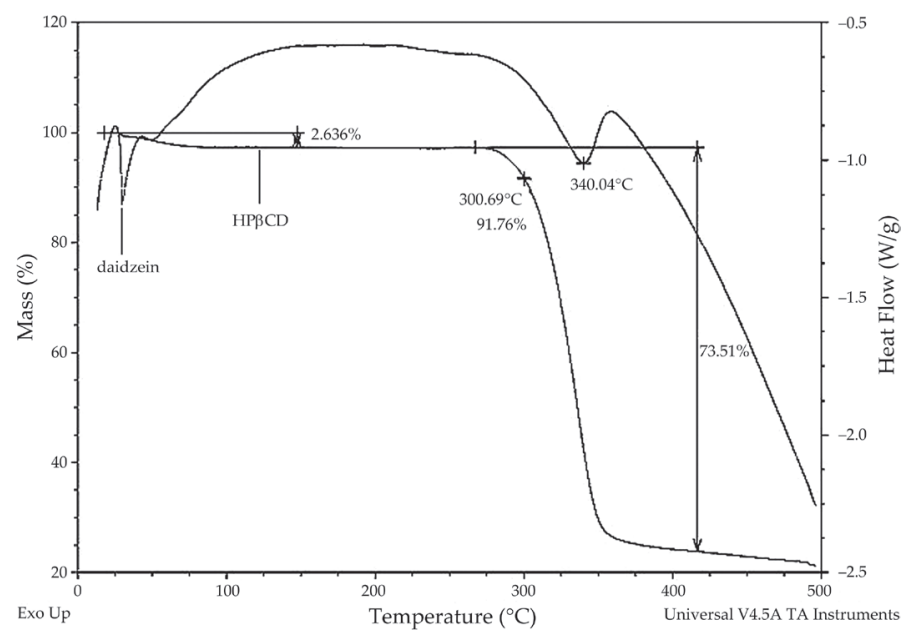

Fig. 3. TGA graphs of daidzein and $\mathrm{HP} \beta C D$. 


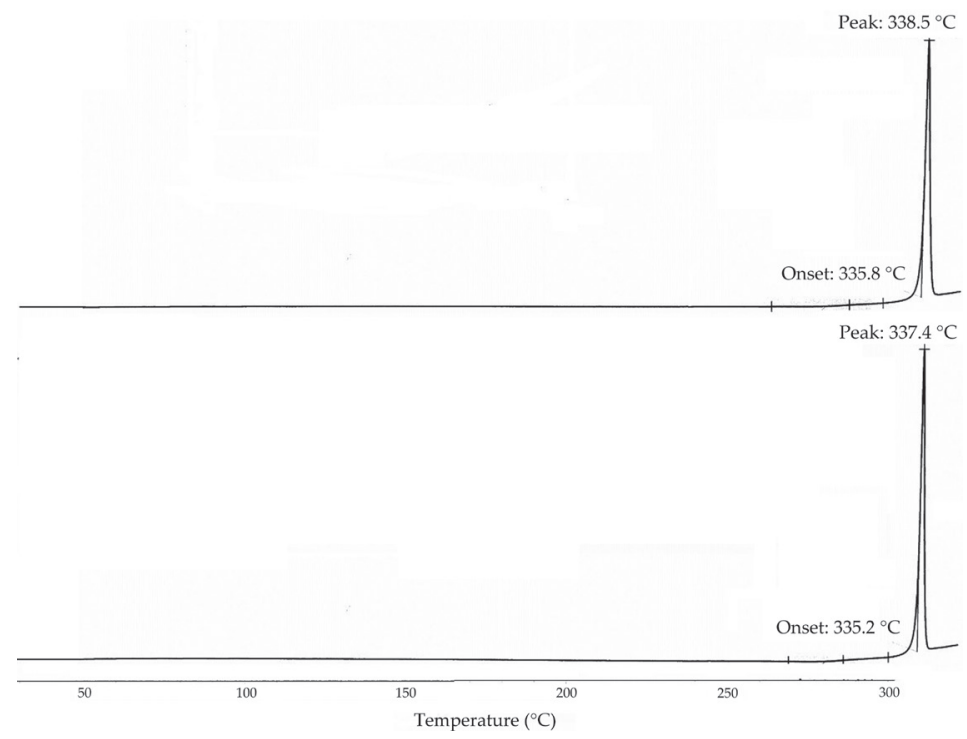

Fig. 4. DSC curves of samples: a) daidzein, b) SCF processed daidzein.

\section{Powder X-ray diffractometry}

The PXRD patterns of raw materials and inclusion complexes are represented in Fig. 5. The diffraction patterns of daidzein and SCF processed daidzein are similar, and display sharp and intense characteristic peaks, confirming the crystallinity of pure daidzein. In agreement with DSC analysis, PXRD analysis indicated that the SC- $\mathrm{CO}_{2}$ process did not alter daidzein crystallinity. The diffraction pattern of HP $\beta C D$ displays two broad halos at $2 \theta$ equal to approximately $10^{\circ}$ and $18^{\circ}$, confirming its amorphous nature. Physical mixtures showed a diffraction pattern similar to that of the respective pure daidzein and $\mathrm{HP} \beta C D$, indicating the existence of crystalline structure of the drug. However, diffraction patterns of the complexes prepared by CSSM and the $\mathrm{SC}-\mathrm{CO}_{2}$ process were characterized by complete disappearance of drug peaks. On the other hand, they displayed two broad features similar to that of pure $\mathrm{HP} \beta C D$, suggesting the possible formation of inclusion complexes in which the daidzein was entrapped in the cavity of HP $\beta C D$. Besides the inclusion complex formation, daidzein amorphisation could also be due to co-precipitation of the binary system leading to amorphous distribution of the drug in HP $\beta C D$ or inhibition of daidzein crystallization in the presence of HP $\beta C D$ during preparation.

\section{Fourier-transform infrared spectroscopy}

The FTIR spectra of the samples are given in Fig. 6. The FTIR spectrum of HP $\beta C D$ showed prominent absorption bands at 3404.1, 2929.7, 2358.8, 2341.4 and $1033.8 \mathrm{~cm}^{-1}$. The FTIR spectrum of daidzein consisted of prominent absorption bands with stretching vibrations of 2341.4, 1631.7, 1595.0, 1517.9, 1460.0, 1238.2, 1191.9, 887.2, 844.8 and $821.6 \mathrm{~cm}^{-1}$. The FTIR spectrum of inclusion complexes prepared by the SCF process (Fig. 6f) is signifi- 
H. Pan et al.: A superior preparation method for daidzein-hydroxypropyl- $\beta$-cyclodextrin complexes with improved solubility and dissolution: Supercritical fluid process, Acta Pharm. 67 (2017) 85-97.

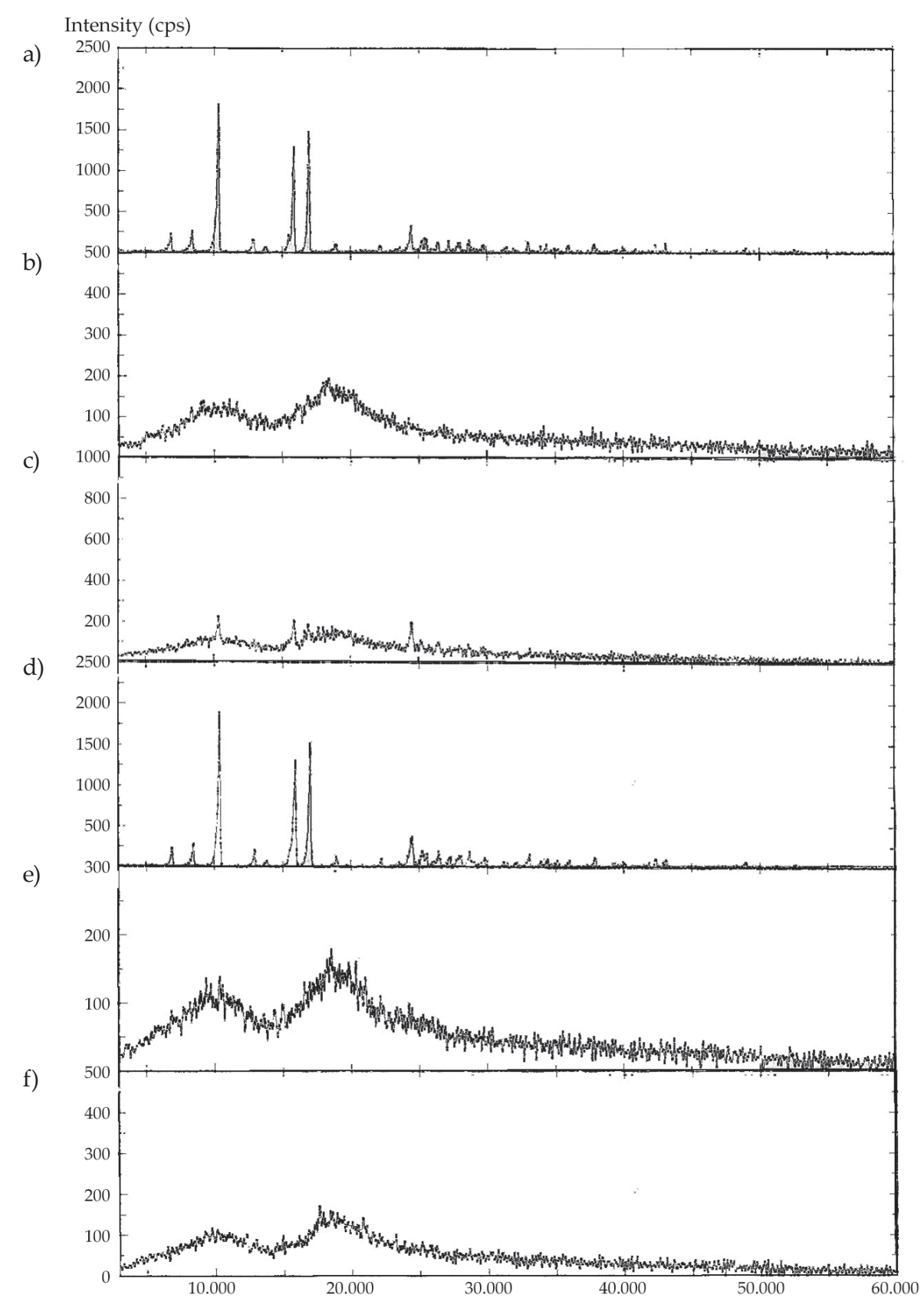

Fig. 5. PXRD patterns of samples: a) daidzein, b) HP $\beta C D$, c) physical mixtures, d) SCF processed daidzein, e) product prepared by the conventional solution stirring method, and f) product prepared by the SCF process. 
a)

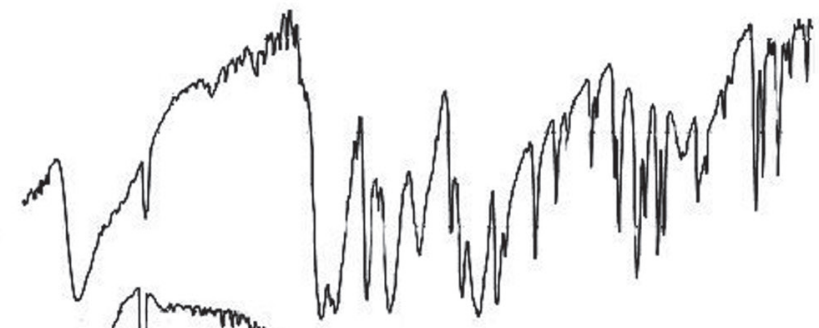

c)

b)

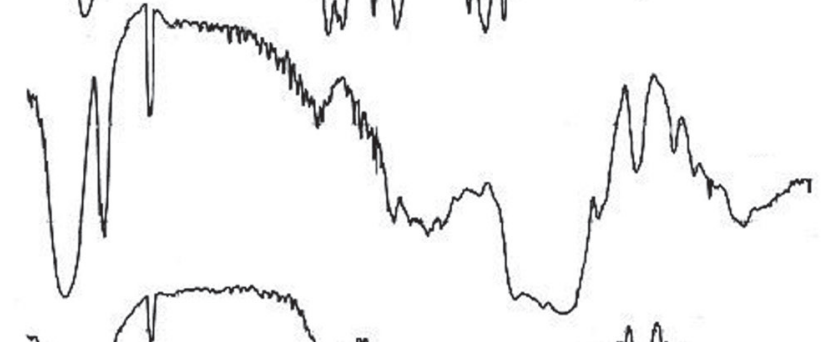

d)
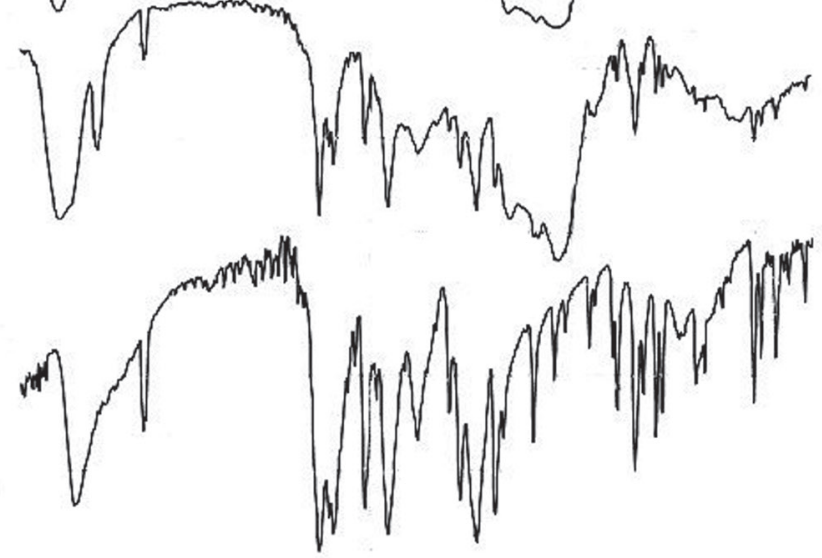

e)

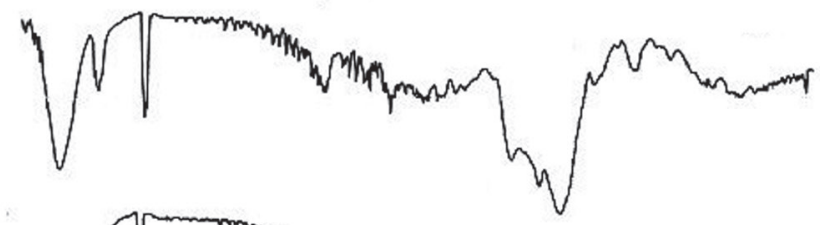

f)

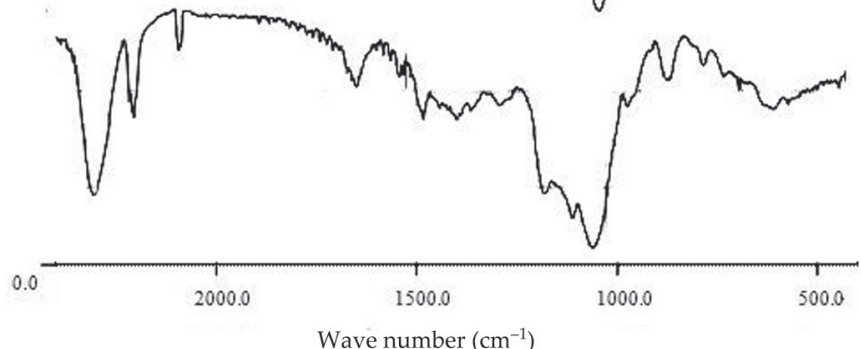

Fig. 6. FTIR spectra of samples: a) daidzein, b) $H P \beta C D$, c) physical mixtures, d) SCF processed daidzein, e) product prepared by the conventional solution stirring method, and f) product prepared by the SCF process. 
H. Pan et al.: A superior preparation method for daidzein-hydroxypropyl- $\beta$-cyclodextrin complexes with improved solubility and dissolution: Supercritical fluid process, Acta Pharm. 67 (2017) 85-97.

a)

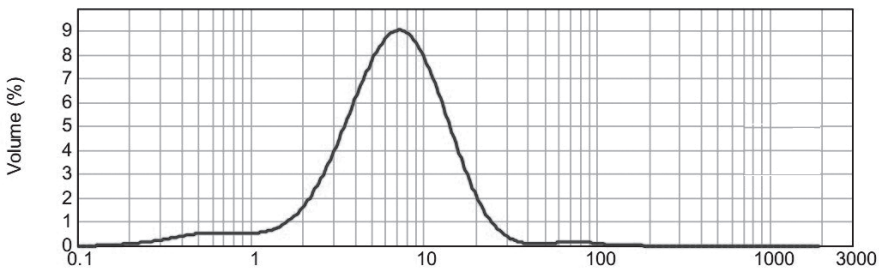

b)

c)
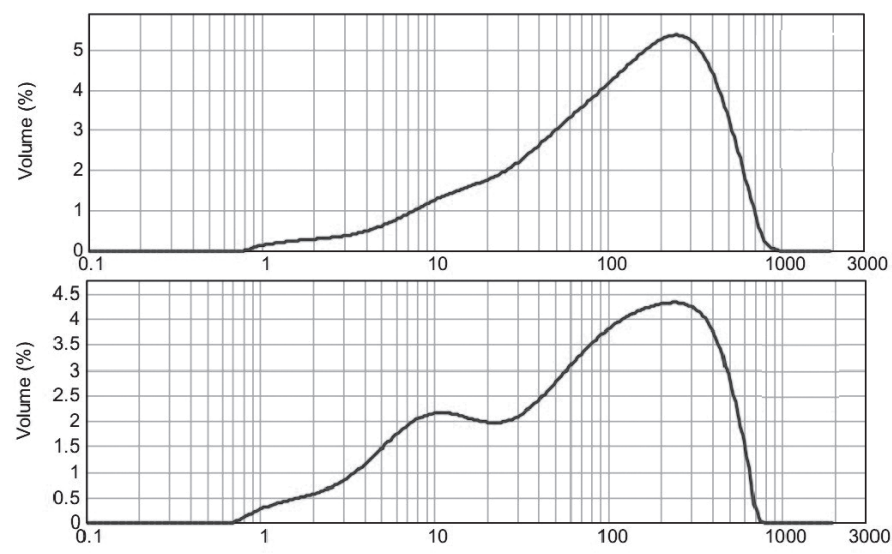

d)

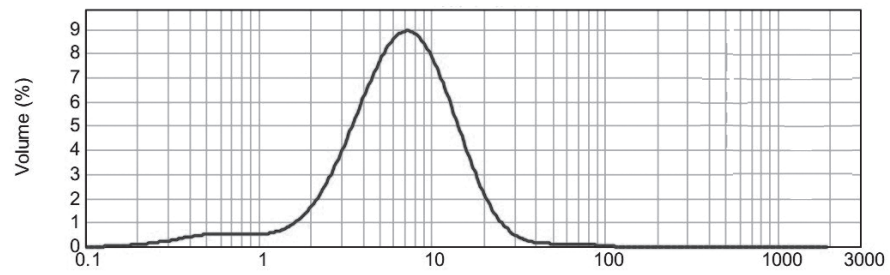

e)

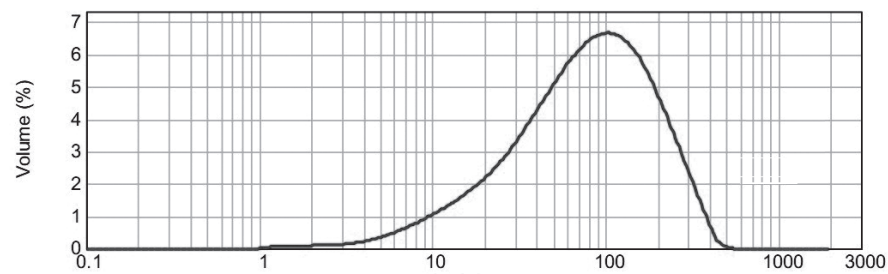

f)

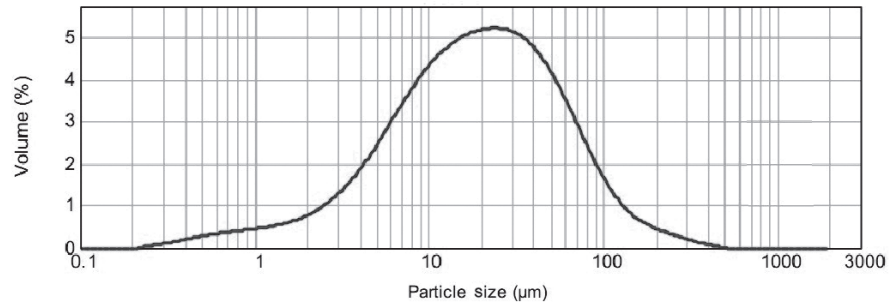

Fig. 7. PSD graphs of samples: a) daidzein, b) HP $\beta C D$, c) physical mixtures, d) SCF processed daidzein, e) product prepared by the conventional solution stirring method, and f) product prepared by the SCF process. 


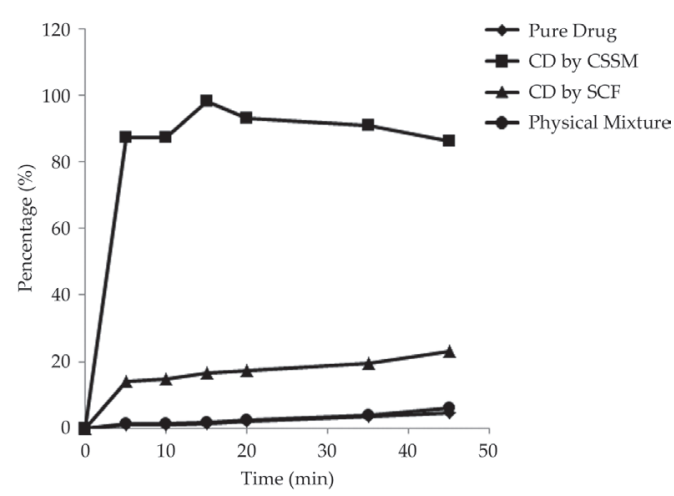

Fig. 8. Dissolution diagrams of daidzein, physical mixtures and inclusion complexes in water at $37^{\circ} \mathrm{C}$.

cantly different from those of daidzein (Fig. 6a) and physical mixtures (Fig. 6c). In the FTIR spectrum of physical mixtures, the $-\mathrm{CH}_{2}$ stretch peak $\left(2929.7,2358.8\right.$ and $\left.2341.4 \mathrm{~cm}^{-1}\right)$ corresponded to those of $\mathrm{HP} \beta \mathrm{CD}$ (Fig. 6b), while $-\mathrm{C}=\mathrm{O}$ vibration peak $\left(1631.7 \mathrm{~cm}^{-1}\right)$ and the peaks at 1517.9 and $1460.0 \mathrm{~cm}^{-1}$ corresponded to those of daidzein, suggesting a superposition of the two compounds. However, compared to pure daidzein, the $-\mathrm{C}=\mathrm{O}$ vibration peak $\left(1631.7 \mathrm{~cm}^{-1}\right)$ and the characteristic peak of the benzene ring $\left(1595,1500\right.$ and $\left.1460 \mathrm{~cm}^{-1}\right)$ in the FTIR spectra of the products prepared by CSSM (Fig. 6e) and the SCF process (Fig. 6f) disappeared, and the spectra were very similar to that of HP $\beta C D$. This revealed that daidzein in the complexes was already entrapped into the cavity of HP $\beta$ CD of both CSSM and the SCF process.

\section{Particle size analysis}

Fig. 7 shows the particle size and size distribution (PSD) of different samples. Differing from the PSD graphs of five other samples, the PSD graph of physical mixtures (Fig. 7c) was bimodal, which indicated the coexistence of both daidzein and HP $\beta C D$. The average particle size of daidzein (Fig. 7a, $8.202 \mu \mathrm{m}$ ) was close to that of SCF processed daidzein (Fig. $7 \mathrm{~d}, 8.400 \mu \mathrm{m})$. The average particle size of the inclusion complex products prepared by CSSM (Fig. 7e) was $173.212 \mu \mathrm{m}$, and the average particle size of the complexes prepared by the SCF process (Fig. 7f) was $32.591 \mu \mathrm{m}$, which was much smaller.

\section{Dissolution test}

Dissolution diagrams of daidzein and daidzein/CDs in water at $37^{\circ} \mathrm{C}$ are shown in Fig. 8. The dissolution behaviour of inclusion complexes and physical mixtures was analysed in comparison with pure daidzein. The results showed that the dissolution of pure daidzein was only $5.30 \%$ after $45 \mathrm{~min}$. The dissolution behaviour of physical mixtures was very similar to the pure drug, while both inclusion complexes prepared by CSSM and by SCF displayed better dissolution properties compared to daidzein alone. However, the products prepared by CSSM showed very rapid release, $87.17 \%$ was released in the first 5 min, and then up to $98.25 \%$ was released in $15 \mathrm{~min}$. In contrast, the products prepared by SCF showed sustained release, with only $22.94 \%$ released for $45 \mathrm{~min}$. 
The inclusion complexes processed by SCF showed extended drug release. This was necessary for the cyclodextrins-based oral drug delivery system. After oral administration, the primary driving force for dissociation of the drug-cyclodextrin complexes is simple dilution and competitive displacement of the drug by biological components in the gastrointestinal fluid (14). All these factors lead to rapid release of the guest molecule. Too fast release of drug molecules from cyclodextrins may induce formation of a precipitate in the GI tract due to the low solubility of daidzein in GI fluids. Moreover, it was difficult for the formed hydrophobic precipitates to penetrate through the GI mucus layer, which has been highlighted as a significant barrier to drug absorption (15). The presence of hydrophobic domains, carboxyl or sulphate groups on the mucin proteoglycans and the flexible nature of mucin fibres lead to hydrogen bonding and hydrophobic and electrostatic interactions with foreign particulates (16). This effectively immobilizes particles in the superficial layer of the mucus. Thus, extended drug release of SCF processed complexes would avoid lipophilic daidzein precipitation in the GI tract, which would be a benefit for its penetration through the mucus layer absorption barrier, and thus enhancement of further mucosal absorption.

\section{CONCLUSIONS}

In this study, the feasibility of the SCF process was investigated for preparing HP $\beta C D$ inclusion complexes of daidzein in order to improve drug solubility. The SEM, DSC, PXRD and FTIR data confirmed the formation of daidzein/HP $\beta C D$ inclusion complexes by the SCF process. Compared to the conventional preparation methods, daidzein/HP $\beta C D$ inclusion complexes prepared by the SCF process achieved higher inclusion yield and drug solubility as well as extended drug release. This is very important for drug solubilisation in the gastrointestinal tract and for its further absorption. Therefore, our results show that the SCF process, as a one-step cyclodextrin inclusion complex preparing process, provides a promising contribution to improving inclusion yield and drug solubility.

Acknowledgements. - This work was supported by the Basic Research Program of the Science, Industry, Trade and Information Technology Commission of Shenzhen Municipality (Grant no. JCYJ20130402145002398) and National Natural Science Foundation of China (Grant no. 81102824).

\section{REFERENCES}

1. S. Soumyakrishnan, T. Divya, S. Kalayarasan, N. Sriram and G. Sudhandiran, Daidzein exhibits anti-fibrotic effect by reducing the expressions of Proteinase activated receptor 2 and TGFbeta1/ Smad mediated inflammation and apoptosis in Bleomycin-induced experimental pulmonary fibrosis, Biochimie 103 (2014) 23-36; DOI: 10.1016/j.biochi.2014.04.005.

2. B. Pahari, B. Sengupta, S. Chakraborty, B. Thomas, D. McGowan and P. K. Sengupta, Contrasting binding of fisetin and daidzein in gamma-cyclodextrin nanocavity, J. Photochem. Photobiol. B. 118 (2013) 33-41; DOI: 10.1016/j.jphotobiol.2012.10.010.

3. X. Dong, W. Xu, R. A. Sikes and C. Wu, Combination of low dose of genistein and daidzein has synergistic preventive effects on isogenic human prostate cancer cells when compared with individual soy isoflavone, Food. Chem. 141 (2013) 1923-1933; DOI: 10.1016/j.foodchem.2013.04.109.

4. H. J. Park, Y. K. Jeon, D. H. You and M. J. Nam, Daidzein causes cytochrome c-mediated apoptosis via the Bcl-2 family in human hepatic cancer cells, Food. Chem. Toxicol. 60 (2013) 542-549; DOI: 10.1016/j.fct.2013.08.022. 
5. B. S. Pan, Y. Y. Kuo, T. Y. Chen and Y. C. Liu, Anti-oxidative and anti-inflammatory activities of two different species of a Chinese herb I-Tiao-Gung, Life Sci. 77 (2005) 2830-2839; DOI: 10.1016/j. 1fs.2005.05.027.

6. M. H. Park, J. W. Ju, M. J. Park and J. S. Han, Daidzein inhibits carbohydrate digestive enzymes in vitro and alleviates postprandial hyperglycemia in diabetic mice, Eur. J.Pharmacol. 712 (2013) 48-52; DOI: 10.1016/j.ejphar.2013.04.047.

7. H. J. Oh, Y. G. Kang, T. Y. Na, H. J. Kim, J. S. Park, W. J. Cho and M. O. Lee, Identification of daidzein as a ligand of retinoic acid receptor that suppresses expression of matrix metalloproteinase- 9 in HaCaT cells, Mol. Cell. Endocrin. 376 (2013) 107-113; DOI: 10.1016/j.mce.2013.06.015.

8. Y. Ma, X. Zhao, J. Li and Q. Shen, The comparison of different daidzein-PLGA nanoparticles in increasing its oral bioavailability, Int. J. Nanomed. 7 (2012) 559-570; DOI: 10.2147/IJN.S27641.

9. T. Loftsson and D. Duchêne, Cyclodextrins and their pharmaceutical applications, Int. J. Pharm. 329 (2007) 1-11; DOI: 10.1016/j.ijpharm.2006.10.044.

10. T. Loftsson and M. E. Brewster, Pharmaceutical applications of cyclodextrins. 1. Drug solubilization and stabilization, J. Pharm. Sci. 85 (1996) 1017-1025; DOI: 10.1021/js950534b.

11. F. K. Yatsu, L. S. Koester, I. Lula, J. J. Passos and R. Sinisterra, Multiple complexation of cyclodextrin with soy isoflavones present in an enriched fraction, Carbohyd. Polym. 98 (2013) 726-735; DOI: 10.1016/j.carbpol.2013.06.062.

12. F. K. Yatsu, L. S. Koester, I. Lula, J. J. Passos, R. Sinisterra and V. L. Bassani, Cyclodextrin-based pharmaceutics: past, present and future, Nat. Rev. Drug. Discov. 3 (2004) 1023-1035; DOI: 10.1038/ nrd1576.

13. S. W. Jun, M. S. Kim, J. S. Kim, H. J. Park, S. Lee, J. S. Woo and S. J. Hwang, Preparation and characterization of simvastatin/hydroxypropyl-beta-cyclodextrin inclusion complex using supercritical antisolvent (SAS) process, Eur. J. Pharm. Biopharm. 66 (2007) 413-421; DOI: 10.1016/j. ejpb.2006.11.013.

14. Q. L. Zhu, T. Guo, D. N. Xia, X. Y. Li, C. L. Zhu, H. Y. Li, D. F. Ouyang, J. W. Zhang and Y. Gan, Pluronic F127-modified liposome-containing tacrolimus-cyclodextrin inclusion complexes: improved solubility, cellular uptake and intestinal penetration, J. Pharm. Pharmacol. 65 (2013) 11071117; DOI: 10.1111/jphp.12074.

15. Q. L. Zhu, X. Y. Li, D. N. Xia, H. Z. Yu, D. Chen, W. W. Fan and Y. Gan, Lipid-based formulations for oral drug delivery: effects on drug absorption and metabolism, Curr. Drug. Metab. 16 (2015) 200-210; DOI: 10.2174/138920021603150812121453.

16. L. M. Ensign, C. Richard and H. Justin, Oral drug delivery with polymeric nanoparticles: the gastrointestinal mucus barriers, Adv. Drug Deliv. Rev. 64 (2012) 557-570; DOI: 10.1016/j.addr.2011.12.009. 